\title{
NOTAS
}

\section{Neruda y Guillén: un Caso de Relaciones Literarias}

$\mathrm{E}$ STE trabajo tiene como meta principal mostrar las vinculaciones de Pablo Neruda y Nicolás Guillén con la moderna historia brasileña. Pero, saltando sobre el mero dato informativo, pretende también penetrar en algunos aspectos del proceso creador de ambos poetas, pues la ocasión se presta a ello en condiciones excepcionales.

$\mathrm{Si}$ los estudios comparativos entre las litertauras de América $y$ Europa han sićo numerosos y podría decirse que el tema casi está agotado, son muy pocos los trabajos dedicados a esclarecer las relaciones literarias entre las diversas comunidades lingüísticas de América. Y sin embargo, los resultados serían - $-\mathrm{y}$ han sido en lo explorado-, espléndidos y sorprendentes. ${ }^{1}$ Bien es cierto, no obstante, que las enormes distancias continenta"es, la escasez de medios de información y el desorden ce bibliotecas y archivos de Latinoamérica descorazonan a cualquiera.

Siendo los Estados Unidos el vértice fundamental del triángulo americano, es comprensible que se haya procurado esclarecer previamente en qué relación se hallan con respecto a él los dos vértices menores: Hispanoamérica y Brasil. De esta forma, la vía comparativa entre los dos bloques ibéricos apenas se ha intentado. Existe una impresión general, derivada de: mutuo e inquietante desconocimiento oficial y de la fragi-

1 Véase, ccmo ejemplo confirmador, el libro del profesor Frederick S. Stimson, Orígenes del hispanismo norteamericano (México: Andrea, 1961), en cuanto a Estados Unidos e Hispanoamérica. 
lidad del hispanismo brasileño, de que los contactos literarios entre Brasil e Hispanoamérica son mínimos e irrelevantes. Pero se trata de un error će visión: más allá de esos aparentes Andes divorciadores e infranqueados, subyacen raices unitivas, vinculos importantes que es necesario poner en claro, que es necesario destacar. ${ }^{2}$ Estamos en un campo apenas entrevisto, pero importante; porque Brasil, por razones que aquí es imposible discutir, ha venido a ser la síntesis de esa tesis y antítesis que son Estados Unidos e Hispanoamérica. ${ }^{3}$ Aventurémonos, pues, a abrir una senda en tan cerrada selva con dos ejemplos preclaros y contundentes de la poesía moderna hispanoamericana.

\section{UiNA VISIÓN DE Río}

Guillén y Neruda han visitado varias veces Brasil. En los periódicos del país han aparecido algunas poesías suyas; abundan las traduc. ciones y hasta existen ciscos de sus poemas recitados personalmente. De esta presencia física, de estos viajes siempre ocasionales, han nacido inevitables poemas a lo más turistico, a lo más llamativo de la nación: la ciudad de Río de Janeiro. Guillén escribe una "Canción carioca", que recoge en La paloma de vuelo popucar, y Neruda compone una "Oda a Río de Janeiro", que inserta en sus Odas elementales.

¿Qué es lo que ven ambos poetas? Prácticamente lo mismo: una belleza natural deslumbrante, a la que se superpone paulatinamente una desconsoladora contemplación social de infinita miseria. Pero, entre los dos, se levanta una enorme distancia estilística y de profundidad ideológica que los separa radicalmente y que demuestra cómo un mismo tema, con idénticos elementos constitutivos, puede ser un fracaso o un éxito artístico conforme el. modo de tratarlo.

2 La causa de una situación de desconocimiento mutuo entre Brasil e His. panoamérica fue agudamente analizada por Silvio Julio en su libro Reąóes na Literatura Brasileira (Rio, 1938). Pero, por otro lado $\mathrm{v}$ sin pretender agotar el tema, sino simplemente apoyar mi afirmación del texto, cabría comprobar esta corriente de relaciones leyendo libros como el de Josue Montello, Ricardo Palma. Clássico da América (Rio, 1954), donde se demuestran contactos entre el escritor peruano y Machado de Assis. O bien, artículos como la serie publicada por el historiador Pedro Calmón en la revista $O$ Cruzeiro en torno a la estancia de Sarmiento en Río. Piénsese aún en la Raza cósmica de José Vasconcelos, escrita después de un viaje por Brasil, o en los seis años cariocas de Alfonso Reyes como embajador de México.

3 Con un ejemplo concreto traté de demostrar esto en mi artículo, "Rubén Darío y el panamericanismo". (São Paulo: Letras Hispánicas, 1962), pp. 5-10. 
Guillén, enumerativo, elemental, con fàtiga de cosas acumuladas en la retina, va preguntando al supuesto lector si ya le han hablado del lujoso y esplendente Río, de sus monumentos, de su carnaval, de sus boîtes. $\mathrm{Y}$ repentinamente, en contraste rotundo, construye su visión social:

Yo te hablo de otro Río:

del Río de Janeiro

de no-techo, sí-frío,

hambre-sí, no-cruzeiro.

La realidad está trasladada con tanta inmediatez, con tanto lastre prosaico, que el poema se nos queda en documento, sin un solo halo poetizador. ${ }^{4}$

Neruda, en cambio, ha intentado sorprender y plasmar la belleza de la ciudad a través će unas imágenes que nos van sugiriendo sus datos plásticos característicos: el agua, la sensualidad, el juego de colores, la fantástica y caprichosa geografía volcánica:

\author{
Río de Janeiro, el agua \\ es tu bandera, \\ agita sus colores, \\ sopla y suena en el viento.
}

Y luego se sumerge en lo social con profundidad interpretativa, centrando el problema en el capítulo clave de la política brasileña: el contraste entre la ciudad abundosa y el resto del país-Nordeste, Amazonas-, pobre, hambriento, abandonado, cosas de las que la "favela" carioca no es sino un aspecto más evidente. Pero todo esto, hondo y claro, se traduce también en imágenes que a veces alcanzan el acierto de ésta:

4 Se ha señalado frecuentemente como mérito esencial de la pcesía de Nicolás Guillén el dominio del ritmo y su sentido social, Cf. Juan Marinello, Literatura Hispanoamericana (Universidad de México, 1957), pp. 81-90); Cintio Vitier, Lo cubano en poesia (Universidad Central de Las Villas, 1958), p. 335; Arturo Torres-Rioseco, New World Literature (Berkeley. University of California Press, 1949), pp. 165-166). Pero, como lo social de por sí no es poético ni artístico, habrá que señalar, en-el estudio completo que la cbra de Guillén reclama, de qué manera hace poesía con lo social. Muy próximo está a quedarse en el subsuelo de lo poético un poeta cuya teoría se resume en:

¿Que sepa el astro en la altura de hambre y frío! 


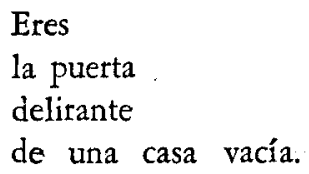

A estas diferencias, que a mi entender señalan muy bien la dimensión artística de ambos poetas, viene a añadirse otra: la posible solución para este esplendor y miseria de Río. Guillén considera la "favela" como un puñal clavado en medio de la ciudad, como un "ojo que ve'a" a 1 a espera de su hora: en sus palabras se trasluce la violencia ce una revolución que lanzará al pobre contra el rico, la destrucción del lujo y la hermosura. Neruda propugna una progresiva ascensión de los de abajo hasta el fastuo ciudadano: belleza y lujo no han de ser destruidos, sino comunicados a todos. Por lo tanto, revolución pacífica frente a revolución sangrienta. Una curiosa diferencia de soluciones en dos poetas, cuya ideología coincide esencialmente.

Para completar este ángulo, que podemos suponer derivaco de los viajes a Brasil, he de referirme al poema "Ciudades" de Nicolás Guillén, inserto también en La poloma de vuelo popular. Se nos habla allí de São Paulo. El enfoque ha sido acertadísimo y, esta vez, surgen unas metáforas justas, precisas. El poeta $\mathrm{fija}$ su atención en la gran avenida central, llamada "Valle de Anhangabaú", que cruzada por innumerables "viadutos" o puentes tendidos para facilitar el tránsito, comunican una personalidad inconfundible a la ciucad. Los "viadutos" se nos convierten en la imaginación transformadora del poeta en "puentes secos", en símbolo de la frustración humana de las multitudes que los recorren a diario, y la urbe industrial, movediza e inquieta en un "saltas" insustituible, sueña en el elemento humanizador que no tiene, el río:

Saltas de puente en puente y sueñas con un río, como una solterona que espera en vano un hijo.

\section{UN PINTOR Y UN POETA}

Fechado en 1947 y en Buenos Aires, recoge Nicolás Guillén en La paloma de vuelo popular otro poema de tema brasileño: "Son para 
Portinari". 'Todo hace sospechar que poeta y pintor se encontraron en la ciudad porteña. ${ }^{5}$ La comunión ideológica brotó inmediatamente: Porti. nari también llevaba a sus cuaćros más representativos, no a la galería de retratos pintados por afanes económicos, una preocupación social. El negro en esclavitud efectiva, el nordestino hambriento y el trabajador mal remunerado del cafetal se nos revelan en los colores ocres o chillones de'. pintor. Este aspecto será, precisamente, el que Nicolás Guillén reflejará con pleno acierto en su poema, escogiendo las palabras ade. cuadas al logro de una correspondencia pictórico-poética. El mundo social del brasileño y su mensaje se desvelan en los versos del cubano en su exacto sentido al mismo tiempo que se precisa su técnica pictórica.

Guillén reitera palabras como "sangre" y "fuigura", queriendo trasladar la sensación cie los colores vivos, especialmente del rojo. El rojo es el color predominante de Portinari, cuando se enfrenta a estos asuntos, como puede verse en los magníficos murales del Ministerio de Río. Rojas son las tierras del Brasil, rojas son las tierras del café, roja es para ellos la esperanza. Aísla después el cubano la representación del hombre, concentrando todas las posibilidades sugeridas por Portinari en un solo individuo ideal: el trabajador, el hombre "će mano dura", fuerte, encallecida, que piensa en sus ensoñaciones revolucionarias, "sueña y fulgura", a pesar de su apariencia sumisa y tranquila de ser derrotado y sometido a la rutinaria existencia mecánica del trabajo. Por último, nos indica la función del pintor brasileño en relación a este hombre: Portinari io "desvela" y lo "cura", es decir, le comunica la inquietud, el malestar, y le señala el camino de su salud social, el remedio de sus problemas.

"Son para Portinari" resulta, pues, uno ce esos felices logros poéticos de Guillén por ser al mismo tiempo una interpretación social y técnica de una obra pictórica y deberá ser tenido en cuenta cuando se trate de ilustrar un caso de correspondencia entre pintura y poesía.

A su vez, fechado en Checoslovaquia y en 1950, Neruda nos of rece un poema dedicado al máximo poeta del romanticismo brasij eño: "Castro Alves del Brasil", que recoge primero en su libro antológico Poesia politica y más tarde incorpora a las Obras completas. Ignoro las circunstancias en que dicho poema se escribió. Quiero adivinar o una traducción

5 Estes datos, como otros que luego señalaré a propósito de Neruda, quedan para la sagacidad de los biógrafos o para los cazadores de epistolarios. Desgraciadamente, ambas cosas, biografía detallada y epistolario, no están a mi alcance. 
de Castro Alves al checo o un encuentro de Neruda con Jorge Amado en Debris. Pero más tarde volveré a este detalle.

La sensibilidad de Neruda sintonizó inmediatamente con la sensibilidad de Castro Alves, como la de Guillén con de Portinari. El chileno descubría un poeta de enorme fuerza social, que en versos robustos, espléndidos, vigorosos, había cantado la libertad del oprimido y había proclamado los derechos del pueblo:

A praça, a praça é do Povo!

Un poeta, en fin, que en acertado resumen crítico de Afranio Peixoto "anunciou a redempção e a liberdade, a emancipação civil dos negros, a emancipação politica dos brancos".?

Pablo Neruda ha hecho una síntesis de los temas poéticos de Castro Alves, enfatizando naturalmente los de contenido social, los que se refieren al ćolor de los negros esclavos y a los derechos del pueblo. Dirigiéndose interrogativamente al brasileño, le pregunta a través de varias metáforas si cantó la hermosura de las cosas, si cantó para la flor, para el agua, para su amada. Y Castro Aives responde afirmativamente, en un breve si, que inmediatamente queda borrado, olvidado tras la amargura y el horror que empañaban la belleza del mundo en sus días:

\section{La primavera estaba salpicada de sangre}

No pudo, pues, cantar la hermosura por la hermosura. Su voz, como Neruda le hace decir a través de las estrofas siguientes c'el poema, tuvo que alzarse en el silencio, golpear ias puertas cerradas de la libertad: "Canté para los esclavos... / Canté en aquellos días contra el infierno". Esta actitud del poeta brasileño, expresada en poemas como "A cançao do africano", "O navio negreiro", Adeus, meu canto" es la que Neruda desarrolla con amplitud. El diálogo entre los dos termina con la aprobación plena del chileno:

Cantaste bien. Cantaste como se debe cantar.

6 Castro Alves, Obras completas (São Paulo, Editôra Nacional, 1938), vol. I. D. 488 .

7 En id, introdução de Afranio Peixoto, p. 11. Puede consultarse sobre Castro Alves, Afranio Peixoto, Castro Alves. O poeta e o poema. $2^{\mathrm{a}}$ ed. (São Paulo, Editôra Nacional, 1942). Y Pedro Calmón, História de Castro Alves (São Paulo, José Olympio, 1947). 
Guillén y Neruda, en consecuencia, orientados por una fina y semejante sensibiliciad social, han centrado su interés artístico en dos figuras diversas de la cultura brasileña, pero equivalentes en cuanto a su actitud ante la sociedad brasileña de sus tiempos respectivos. $Y$ las han celebrado, sintiendo su propia afinidad con ellas.

\section{UN CAPÍtTULO BRASILEÑo EN EL CANTO GENERAL}

Dejando aparte la estrofa dedicada al Amazonas cuando Neruda canta los ríos de América, el capítulo brasì eño del Canto General está constituido por los poemas "Dicho en Pacaembú", "Prestes del Brasil", "De nuevo los tiranos" y "Brasil". Este capítulo, aunque breve y artísticamente no bien logracio, se reviste de suma importancia porque nos sumerge de lleno en algo poco estudiado todavía: el proceso creador en sí del poeta chileno. ${ }^{8}$

Admitamos un presupuesto, al parecer indiscutible: el Canto Genera' tiene carácter épico, aunque no sea strictu sensu una epopeya. Siendo así, el paisaje sólo ha de interesar como escenario, como fondo, o bien, en cuanto sea personificación de una tragedia humana, símbolo perdurable de la misma. Neruda alude brevemente al paisaje brasileño, da acuerdo con el primer criterio: destaca en él la inmensićad, el gigantismo del país, su tropicalismo selvático y fecundo. El Amazonas será "capital de las sílabas del agua" mientras Brasil emerge entre sus "hojas gigantes / en desarrollo vegetal".

Pero lo que al cantor épico le interesa realmente son los hechos históricos en su dimensión política, porque toda épica en su motivación remota es esencialmente política. Si celebra la historia de su patria, de su región o de su mundo, lo hace bajo la luz de su interpretación personaí acorde con una visión política. La objetividad épica sólo existe en la crítica literaria como línea definitoria frente a la mayor subjetividad ce la lírica. Pero la épica, que deforma los hechos, exaltándolos o denigrándolos, que divide a los protagonistas en buenos y malos muchas

8 Abundantisima es la bibliografía sobre Neruda $y$ hay libres fundamenta'es como el conocidísimo de Amado Alonso sobre su estilo o el de Roberto Salama. Para una critica de Pablo Neruda (Buenos Aires, ed. Cartago, 1957). Pero ni siquiera en éste, que tan pormenorizadamente demuestra el carácter épico del Canto General, existen alusiones al proceso creador en sí. Bastante inconcretos en cuanto al problema. son libros que narran la vida en relación a la obra, como el de Jean Marcenac, Pablo Neruda (París, ed. Pierre Segnels, sin fecha). 
veces con simple criterio nacionalista, no contiene otra objetividad que la de basarse remotamente en la historia real o fabulosa. De aquí parte para transformar ia realidad en idealidad, en esencia representativa $y$ purificada, en anhelo, en mito. Los poetas épicos cantan para encender la fe nacional de los pueblos, para fomentar su entusiasmo patriótico, para conducirlos a una interpretación determinada del pasado.

Pues bien, esto se cumple casi ejemplarmente en el Canto General. Cuando un crítico como Roberto Salama afirma que "Neruća es objetivo y tendencioso"," me parece que sólo acierta en la segunda palabra, pues siendo tendencioso, no puede ser objetivo. Neruda es, antes de nada, tendencioso y subjetivo: habla bien de lo que está de acuerdo con su ideología; condena rabiosamente lo que no se acomoda a elia. De ahí deriva la exaltación de su propio mito, el mito de la concepción comunista del mundo como única progresista y aceptable, porque, como bien afirma el mismo Roberto Salama, "el partido dota a Pablo Neruda de una ideología marxista-leninista que le permite descubrir por sí solo el meollo de l'a realidad" y0 $^{10}$ Pero el realismo marxista, con su aparente objetividad, es tan subjetivo como cualquier otra interpretación de la realidad; por eso, Neruda sólo tendrá ojos para lo suyo, sus compañeros o aquello en lo que vea un sentido social próximo al suyo.

La consecuencia práctica en cuanto a lo que aquí tratamos, imposible de deducir sin haber establecido las proposiciones anteriores, no es otra que ésta: de toda la moderna historia brasileña, Neruda ha seleccionado un brevísimo apéndice, dejando en la sombra del olvido todo lo demás. La mutilación empequeñecedora, con todos sus corolarios, es evidente. Unicamente nos habla de Luis Carlos Prestes, fundador del partido comunista brasileño. A través de "Dicho en Pacaembú" y "Prestes del Brasil", éste se transforma en un héroe auténtico: todos los obreros del mundo lo veneran; todos los países de América lo proclaman, como Brasil, "cabalero de la esperanza"; todos los hombres le llevan un mensaje, un saludo. Porque ha sido grande; porque ha realizado la sin par hazaña de la marcha por la selva con su famosa columna, teniendo en jaque a las fuerzas del Presicente Bernardes; porque ha sufrido el tormento; porque, en fin, el pueblo lo adora:

9 Op. cit. p. 219.

10. Op. cit. p. 136 . 
Vivió su nombre como un árbol

en medio de todo su pueblo

reverenciado y esperado.

Frente a él, sus opositores, sus enemigos serán condenados como monstruos: Bernardes es el "tirano de los ojos pálidos", mientras en el poema "Brasil", el presidente Dutra se nos convierte en:

El Dutra, el pavoroso

Pavo de las tierras calientes.

Es claro, por lo tanto, el carácter mitificador del Canto General: ni Bernardes ni Dutra, presidentes constitucionales de Brasil, se cuentan entre los peores de la república tropical. Sus gobiernos fueron relativamente progresistas y mocierados. Por otro lado, nunca Prestes fue visto por el pueblo brasileño como solución de sus problemas ni tuvo otra popularidad que la concedida por una minoría inquieta en las contadas ocasiones de los homenajes, de los que el rendido en el estadio paulista de Pacaembú, en 1945, marca el ápice. La Columna que atravesó la selva en lucha contra el gobierno, en 1925, bajo el mando de Prestes, no tiene de hazaña militar otra cosa que lo que pueda tener una guerrilla contra una tropa no habituada a tal estrategia: lo demuestra que Prestes nunca se batió en campo abierto ni en las ciuciades y el haber tenido que internarse en Colombia como solución más honrosa a una acción que el tiempo aniquilaba.

Ahora bien, esta mutilación histórica, este centrarse en sucesos accesorios, origina una clara frustración de la grandeza épica que Neruda consigue en momentos más certeros de su Canto General: el abismo entre la realidad y el mito es tan grande que no existe potencia imaginativa capaz de salvarlo. Quizá así podamos comprender que el Canto General sea una sucesión de éxitos y fracasos conforme la mirada partidista del poeta se fije en hechos fundamentales de la historia americana o en nimiedades intranscendentes. No se trata de discutir lo acertado - lo errónco del punto de vista político de Neruda, sino de sus posibilidades o limitaciones artísticas en relación con su interpretación de la historia americana.

\section{JoRge Amado y Pablo NERUdA}

Para terminar este estudio de relaciones literarias, he de referirme a un delicado problema, cuya solución es, desde luego, muy discutible, 
sobre todo, por carecer de documentos externos como cartas o testimonios directos que apoyen la hipótesis que voy a sugerir. Es sabido que a Pablo Neruda y al novelista brasileño Jorge Amado les ha unido desde hace mucho tiempo una sólida amistad: en varios lugares del mundo y en diversas ocasiones, las fotografías nos los muestran juntos. Cabría preguntar: ¿en qué medida influyó Jorge Amado en los poemas que Neruda dedicó a asuntos brasileños?

La pregunta no es ociosa. Jorge Amado es el autor de una biografía épica de Luis Carlos Prestes que apareció en castellano, en Buenos Aires, el año r942, con a! título de Vida de Luis Carlos Prestes."1 Es anterior a cuanto Neruda escribió sobre Brasil y nadie debe dudar de que la conocía. Pues bien, esa transformación heroica de Prestes, esa conversión en caballero de la esperanza, esa relevancia de todos sus hechos hasta los más mínimos, ese valor de símbolo del pueblo, que Neruda le da en el Canto General, están nítidamente dibujados en la Vida escrita por Jorge Amado. $\mathrm{Y}$ no sólo esto: hay, además, algunos pasajes concretos que hacen pensar en la relación directa de las dos obras. Jorge Amado elige la imagen de la estrella para identificarla con la esperanza que es Prestes. Curiosamente, Neruda inserta esta misma imagen en los poemas dedicados al político brasileño:

Aquella noche oscura tuvo estrellas:

las estrellas humanas, las lámparas del pueblo.

"Estrela na noite negra, temporal do povo" (p. 23) habia escrito Jorge Amado.

En tono enumerativo repite Neruda hechos que Jorge Amado narra con abundancia de detalles, como si quisiera resumirlos: la separación ce Prestes y su esposa a'emana que fue entregada al gobierno nacista, el nacimiento de la hija en una cárcel alemana, los sufrimientos psíquicos del prisionero. El biógrafo cierra su narración con la frase "não tem coragem para fuzilá-lo", que literalmente traduce el poeta, concluyendo también su enumeración: "sin atreverse a fusilarlo".

Jorge Amado hace una critica violenta en su Vida de Luis Carlos Prestes de todos aquellos escritores brasileños que prefieren cantar temas

11 Cito por la edición brasileña, Vida de Luiz Carlos Prestes (Săo Paulo, ed. Martins, 1945), que no altera el contenido de la edición argentina de 1942. 
exóticos como Grecia y sus héroes en vez de adentrarse en la esencia y los sufrimientos de su pueblo. $Y$ por contraste elogia ditirámbicamente a Castro Alves. Dice en una ocasión a propósito de éste: "um povo que não podia falar precisando de uma voz que clamasse, fez o milagre da mais bela das vozes" (p. 2I). No deja de ser extraño que Neruda, en uno de sus poemas sobre Prestes, se extienda en esta consideración:
Poeta, buscas en tu libro
los antiguos dolores griegos...
$Y$ no ves en tu propia puerta
los océanos que golpean
el oscuro pecho del pueblo

Exactamente lo mismo que Jorge Amado, como puede comprobarse. Pero, además, en I950, Neruda escribirá, como antes dije, su poema "Castro Alves del Brasil" y en él encontraremos este verso cuya coincidencia con las palabras recién transcritas del brasileño me parece innegabie:

\section{Y era mi voz la única que llenaba el silencio}

En conclusión, si todas estas coincidencias no son meros espejismos míos, creo que se puede hablar de un caso de relaciones literarias y, así, podría efectuarse una exploración poco desarrollaca todavía en torno a la poesía de Pablo Neruda: la de sus fuentes, lo que aclararía no poco su manera de crear. Esto es lo que he intentado hacer en relación con un punto concreto de su obra.

\section{CONCLUSIONES}

El análisis que acabamos de realizar nos permite establecer a guisa de resumen las siguientes conclusiones:

I. La presencia de Brasil en la Literatura Hispanoamericana es una realidad que hay que tener en cuenta, pues su investigación no deja de tener resultados críticos válidos.

2. Neruda y Guillén, poetas sociales de ideologia muy concreta, nos han dejado una visión social de Brasil a través de sus ciudades, de artistas como Portinari o poetas como Castro Alves, y políticos como 
Prestes. No siempre esta visión social alcanza resultados artísticamente válidos, pues a veces lo social se refleja con una inmediatez antipoética.

3. El capítulo brasileño del Canto General representa una concepción mutilada y estrecha de la historia moderna del Brasil: mitifica una figura de importancia secundaria dentro de su desartollo. Y con ello se llega también a un fracaso poético.

4. Parece evidente la influencia ejercida por Jorge Amado sobre Neruda en su visión del Brasil moderno y sus figuras.

Nortbwestern University

RICARDO NAVAS-RUIZ 